\title{
Pineal Gland-A Spiritual Third Eye: An Odyssey of Antiquity to Modern Chronomedicine
}

\author{
Raj Kumar $^{1}$ Arushi Kumar ${ }^{1} \quad$ Jayesh Sardhara ${ }^{1}$ \\ ${ }^{1}$ Department of Neurosurgery, Sanjay Gandhi Postgraduate Institute \\ of Medical Sciences, Lucknow, Uttar Pradesh, India
}

Address for correspondence Raj Kumar, MCh, Professor and Head, Department of Neurosurgery, Sanjay Gandhi Postgraduate Institute of Medical Sciences, Rae Bareli Road, Lucknow, Uttar Pradesh, India (e-mail: rajkumar1959@gmail.com).

\begin{abstract}
Keywords

- pineal gland

- third eye

- chronomedicine
\end{abstract}

Pineal gland or "spiritual third eye" is regarded as the gateway of spiritual life as per ancient concepts about the soul. Recently, modern neuroscience has proven that pineal gland is not only the melatonin-secreting neuroendocrine organ which controls the circardian rhythm, but it also has mystical and energetic associations with spirituality. It acts as a tremendous coordinator between molecular, hormonal, physiological, and chemical rhythmic orchestra. Thus, in this article, by highlighting the relation between ancient Indian methodology and modern chronomedicine, the author describes the odyssey of antiquity to modern science.

\section{Background}

Dimethyl tryptamine from the pineal gland is also known as spirit molecule. It is linked to perception and is activated by energetic and magnetic frequency. It may sound absurd to some researchers, but current evidence favors existence of the "third eye." 1 The literature is flooded with articles relating the pineal gland with circadian rhythm. In this article, the author has highlighted the bonding between ancient Indian methodology and modern chronomedicine. The description of "Ham and Ksham" and its correlation with pineal gland and hypothalamic-pituitary complex highlight the odyssey of antiquity to modern chronomedicine.

\section{Historical Aspect}

Human beings have a "third eye" or mystic body scientifically known as the pineal gland. The third eye corresponds to sixth "chakra"-"Ajna" that provides a "window" into the spiritual life of every individual ( - Fig. 1). The ancient scientists had never believed in the existence of the soul until Cartesian neuropsychophysiological doctrine was laid in the 17th century. The two schools of science and philosophy gave common consensus on the existence of the pineal gland and its physiologic and mythological importance. ${ }^{2}$
The ancient philosophers and scientists have a different belief in the soul and its existence. The exact seat of the soul has evolved over centuries. The Platonic and Aristotle concepts highlighted the three types of souls concluding the importance of the heart as the center of control-"Phren." ${ }^{3}$ According to them, the soul is outside the body and linked with the materialistic body with some part. It was Hippocrates, who changed their concept and said that soul resides somewhere inside the body. Hippocrates justified that it is the brain, rather than the heart, as the focal point of feeling and reason. The "soul" is the energy-generating part that coordinates the molecular, hormonal, physiologic, and chemical orchestra of the human body. Modern neuroscience believes that the rhythmic coordination is maintained by suprachiasmatic nucleus, via the pineal gland, thus the pineal gland has mystical and energetic associations. ${ }^{4}$

The first specific reference to the pineal gland was given by Herophilus who wrote that the soul is in "kalamos." The detailed description of the pineal gland was given by Galen in his work "De anatomicis administrationibus." He believes that the soul flows in form of air from the lungs to the heart and then to the brain. The flow of air in the brain is controlled in valve-like fashion by the pineal gland.

The importance of the pineal gland as a center of soul reached its peak in the era of Saint Thomas Aquinas (1225-1274 AD) who formed a council and proved his

\section{received}

January 14, 2018

accepted after revision

March 6, 2018
DOI https://doi.org/

10.1055/s-0038-1649524.

ISSN 2277-954X.
Copyright @2018 Neurological

Surgeons' Society of India
License terms

(1) $\Theta \circledast$ 


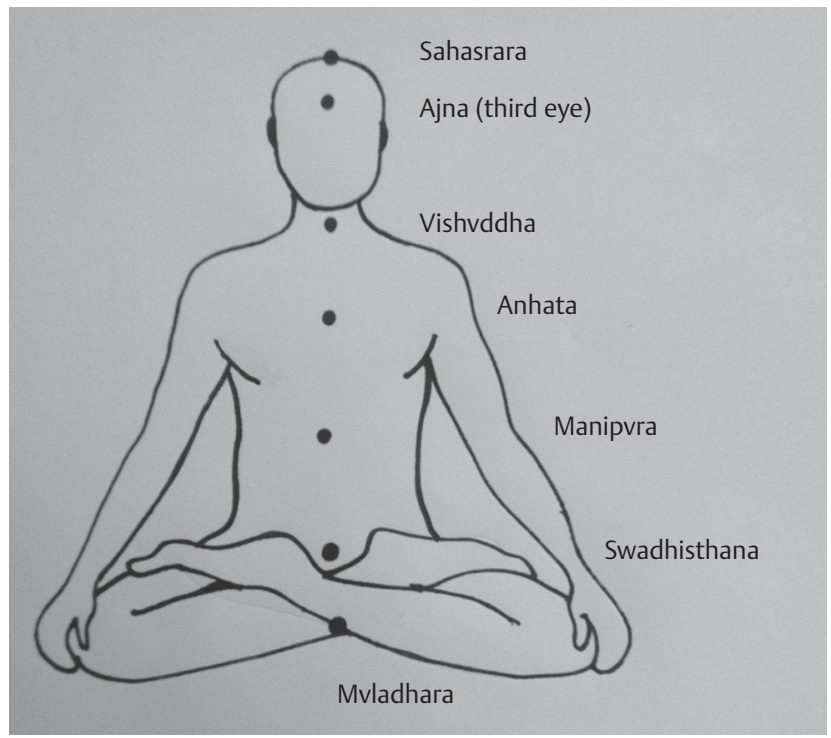

Fig. 1 Diagrammatic presentation showing the seven "Chakras" in human being.

"theory of three cells." Later on, Descartes and Andreas Vesalius (1514-1564 AD), the father of modern anatomy, also proposed the brain as the center of the soul. ${ }^{4}$ Rene Descartes in his book The Passion of Sole described the pineal gland as the meeting place of the physical and spiritual worlds and wrote that "The body and spirit not only meet there, but each affects the other and the repercussion extends in both directions."

\section{Ancient Indian Mythology and Chronobiology}

The three main "Nadis" are Ida, Pingla, and Sushmna. These Nadis are the subtle energy channels of the body, and they conduit "Prana" (soul) throughout the whole body. ${ }^{5}$ Ajna Chakra, the area of the third eye, is the sixth Chakra, which is found in the space between the eyebrows (Brow Chakra, the third eye, the eye of wisdom, the inner eye Chakra, or the command Chakra). An invisible yet powerful third eye, this is our center of intuition. ${ }^{2}$

The letter "ham" represents Shiva. "Ksham" represents Shakti. These two words written on petals represent the manifest and the un-manifest mind and are sometimes said to represent the pineal and pituitary glands.

Actually, as human beings, we do not know the power of the mind. Ancient "gurus" have gained mystic and supernatural powers by igniting the third eye. ${ }^{6}$ Although substantial evidence is missing, the scientific world has a strong inclination toward the existence of Ajna chakra or third eye. We probably possess an intense capacity for visualization, and our mind is composed and opens to mystic truths. We realize more and more that the world of appearances is but an allegory, a symbol of a spiritual principle manifested on the physical level. We possibly notice from time to time that our thoughts or ideas come true. Some people called it déjà vu. The more our third eye Chakra develops, the more our thoughts are based on a direct inner awareness of reality. ${ }^{6}$

\section{Rhythmicity and Circadian Rhythm}

The term "circadian" comes from the Latin ca., "around," and Diem or dies, "day," meaning literally "approximately one day." The formal study of biological temporal rhythms such as daily, tidal, weekly, seasonal, and annual rhythms is called chronobiology.

Chronomedicine is prescribing medicines at specified clock hours to achieve an optimization of therapeutic administration. Rhythmicity is seen in metabolic pathways and serum chemical levels inside the human body. It is also seen in the sensitivity of target systems to endogenous or exogenous chemical substances. ${ }^{8}$ It is proved that plasma proteins also undergo a circadian rhythm so drugs binding to these plasma proteins follow rhythmicity. For example, antihypertensive drugs expressing first dose phenomenon are usually administered at bedtime to avoid complications due to hypotension.

\section{Role of Pineal Gland in Maintaining Circadian Rhythm}

The pineal gland is the neuroendocrine organ that primarily functions to maintain circadian rhythm and provide "light and dark" information to the rest of the brain through hormone melatonin. The melatonin is derived from amino acid tryptophan, and its formation is controlled rhythmically by the hypothalamus and pineal gland. The melatonin shows rhythmic secretion and control in following four steps. The rhythmicity is controlled both locally (enzymes) and centrally by suprachiasmatic nuclei of the hypothalamus. ${ }^{9}$

1. Dietary amino acid tryptophan to 5-hydroxytryptophan (5-HTP) by tryptophan hydroxylase 1 (TPH1).

2. Synthesis of 5-hydroxytryptamine (5-HT or serotonin) by aromatic amino acid decarboxylase.

3. Formation of $N$-acetylserotonin (NAS) by arylalkylamine $\mathrm{N}$-acetyltransferase (AANAT).

4. Production of melatonin by hydroxyindole-O-methyltransferase (HIOMT) (also termed N-acetylserotonin methyltransferase [ASMT]).

Circadian signals from the SCN are transmitted sequentially to the paraventricular nuclei, the intermediolateral nucleus of the spinal cord, superior cervical ganglion, and then finally the pineal gland. The pineal gland is also innervated by parasympathetic system. ${ }^{9}$ Apart from light and parasympathetic system, melatonin rhythm is coupled tightly to the core temperature rhythm with the peak of melatonin secretion corresponding closely to the nadir of temperature. ${ }^{10}$

\section{Retinohypothalamic Tract and Chronodisruption}

The intrinsic cycle of electrical activity of suprachiasmatic nucleus is closer to 25 hours rather than 24 hours. ${ }^{11}$ Thus, the neural "clock" runs slow, and if this rhythm is not be adjusted nearer to a 24-hour cycle, the physiology of the 


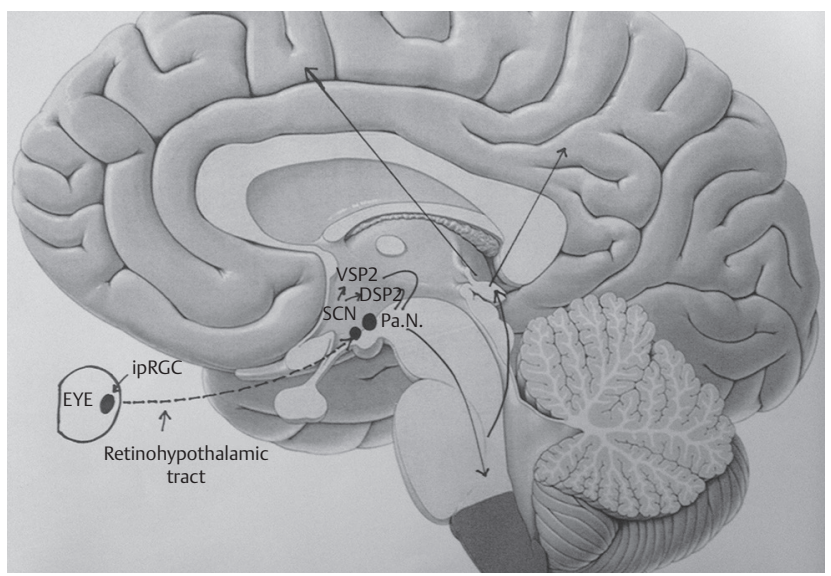

Fig. 2 Retinohypothalamic track pathway: intrinsically photosensitive retinal ganglion cells (iPRGC) $\rightarrow$ suprachiasmatic nucleus $(\mathrm{SCN}) \rightarrow$ dorsal and ventral subparaventricular nucleus (DSP and VSP) $\rightarrow$ cervical ganglion $\rightarrow$ pineal gland $\rightarrow$ melatonin.

organism would quickly be "out of phase" with the standard time. The pathophysiological process is called as desynchronized or chronodisrupted. This highlights the need of some organ to maintain neural clock into the circadian rhythm. This pathway is known as retinohypothalamic tract (RHT) ( - Fig. 2). ${ }^{12}$ In this pathway, the light is perceived by highly specialized intrinsically photosensitive retinal ganglion cells (ipRGC). These cells involved in synchronizing the neural clock consists of the small percentage (1-2\%) of the total ganglion cell population, and they contain their own specialized photopigment, melanopsin. Melanopsin is further different in that it does not respond to blue range wavelength, roughly 460 to $480 \mu \mathrm{m}$ wavelength of light only. ${ }^{10}$ The axons of these neurons travel in the optic nerve to the level of the optic chiasm where they then diverge to penetrate the SCN where they make synaptic contact with clock neurons. From the SCN, it passes via the paraventricular nuclei, the upper thoracic intermediolateral cell column of the spinal cord, and then sympathetic neurons of the superior cervical ganglion, which innervate the pineal. This series of connections linking the retina to SCN to pineal gland is sometimes referred to as a photoneuroendocrine system.

When the photoperiodic environment is artificially perturbed, for example with light exposure during the normal dark period, the central circadian pacemaker receives inappropriate information for that time, and melatonin suppression and circadian disruption results. The chronodisruption leads to change in the physiology of human body leading to ill health known as diseases of decrease melatonin activity. ${ }^{13}$

\section{Sequelae of Chronodisruption}

In chronobiology, light is the major zeitgeber ('time giver') affecting the alignment and entrainment of circadian rhythms in children and adults.

One particular disease that has frequently been discussed relative to excessive or abnormal light exposure is cancer. The International Agency for Research on Cancer has classified

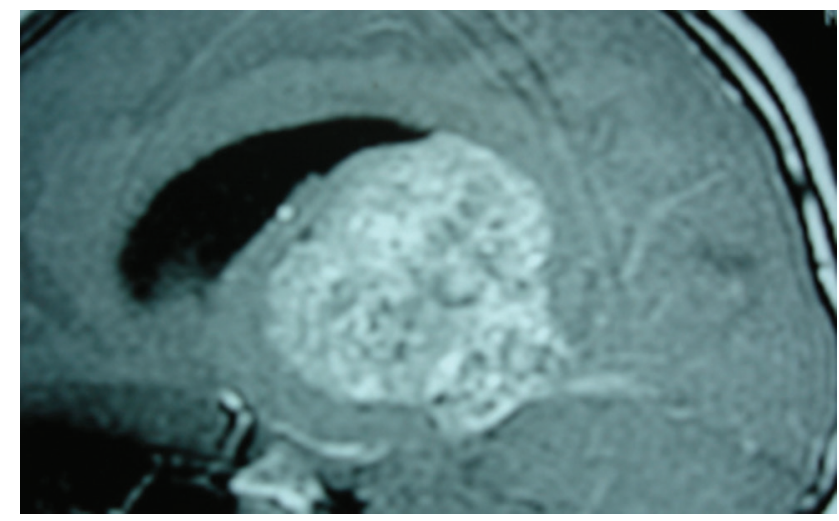

Fig. 3 Representative magnetic resonance imaging showing a pineal gland tumor arising from and expanding the third ventricle of the brain.

light at night as a group 2A carcinogen, that is, a probable carcinogen in humans ${ }^{14}$ (-Fig. 3 ).

The free radical scavenging action of melatonin and its antioxidant effect finds its role in the protection of the mucosa of the gastrointestinal tract (GIT) being generated and released by the EE cells of the GIT in enormous amounts to portal circulation to protect the liver and biliary tract from various irritants. ${ }^{10}$

The rhythmicity of melatonin level not only predicts daynight cycle but also acts as the marker of seasonal calendar. The contrast between short-duration signals in the summer and long-duration winter signals is both necessary and sufficient to drive subsequent seasonal rhythms in diverse processes such as reproduction, metabolism, and immune function. The phenomenon of "jet lag" is linked to chronodisruption. Melatonin has the role in antiaging phenomenon via its free radical scavenging effects. ${ }^{13}$

\section{Circadian Rhythm and Ayurveda}

The Ayurvedic physiology and pathology are based on the circadian rhythm of three "Doshas." According to Sushruta, these doshas govern the physiologic integrity of body by controlling the distribution of energy, in the same way as soma, Surya, and Anila maintain the integrity of the terrestrial world. The three doshas-Vata, Pitta, and Kapha-follow a circadian rhythm, and by this rhythm, all the metabolic functions of the body are regulated. Disruption in this rhythm leads to the production of various pathologic states. Beside daily circadian rhythm, these doshas also follow the circannual rhythm and yearly cycle by the process of their "Sanchaya," "Prakopa," and "Shaman" for regulating the biochemical, physiologic, or behavioral processes of the body. Our sleep depends on Kapha and Tama Doshas, and if the time of "Kapha predominance" passes, one feels the state of awareness and leading to vitiation of "Vata."15 Vitiation of Vata leads to the development of "Rakshasa" in the body and symptoms such as irritability, restlessness, and arduousness in concentrating, facile fatigability develop in the person. If it is done only for 1 or 2 days a week, the body can adjust it by taking day sleep (Divaswapa). ${ }^{16}$ However, if it becomes our quotidian routine, our cycle of Doshas is inverted and disease develops. ${ }^{8}$ 


\section{Conclusion}

The existence of the pineal gland as third eye or mystic control has been described in Indian ancient science. ${ }^{17}$ The modern world is trending toward the same inference. Circadian rhythm, its maintenance, and role of melatonin are important in controlling the normal physiology of the body. Further melatonin has shown pharmacologic uses as anticancer and antiaging agents. Its role in preventing osteoporosis and menstrual irregularity is under trials. The author believes that someday the modern science could decode the mystery of "third eye" completely, and he intends to find the solution for supernatural controls also.

\section{Conflicts of Interest}

None.

\section{Prior Publication}

None.

\section{Support}

None.

\section{Permissions}

None.

\section{References}

1 Jangir OP, Suthar P, Shekhawat DV, Acharya P, Swami KK, Sharma M. The "third eye"-a new concept of trans-differentiation of pineal gland into median eye in amphibian tadpoles of Bufo melanostictus. Indian J Exp Biol 2005;43(8):671-678

2 López-Muñoz F, Rubio G, Molina JD, Alamo C. [The pineal gland as physical tool of the soul faculties: a persistent historical connection] [in Spanish]. Neurologia 2012;27(3):161-168

3 Ashok AH, Baugh J, Yeragani VK. Paul Eugen Bleuler and the origin of the term schizophrenia (SCHIZOPRENIEGRUPPE). Indian J Psychiatry 2012;54(1):95-96
4 Prus R. Aristotle's theory of deviance and contemporary symbolic interactionist scholarship: learning from the past, extending the present, and engaging the future. Am Sociol 2015;46(1):122-167

5 Hankey A. Establishing the scientific validity of Tridosha part 1: Doshas, Subdoshas and Dosha Prakritis. Anc Sci Life 2010;29(3):6-18

6 Srinivasan TM. Pranayama and brain correlates. Anc Sci Life 1991;11(1-2):2-6

7 Lefta M, Wolff G, Esser KA. Circadian rhythms, the molecular clock, and skeletal muscle. Curr Top Dev Biol 2011;96:231-271

8 Arora D, Kumar M. Concept of chronopharmacology in ayurveda. Anc Sci Life 2000;19(3-4):155-163

9 Borjigin J, Zhang LS, Calinescu A-A. Circadian regulation of pineal gland rhythmicity. Mol Cell Endocrinol 2012;349(1):13-19

10 Hardeland R. Neurobiology, pathophysiology, and treatment of melatonin deficiency and dysfunction. Sci World J 2012;2012:640389

11 Evans JA, Gorman MR. In synch but not in step: circadian clock circuits regulating plasticity in daily rhythms. Neuroscience 2016;320:259-280

12 Morin LP. Neuroanatomy of the extended circadian rhythm system. Exp Neurol 2013;243:4-20

13 Reiter RJ, Rosales-Corral S, Coto-Montes A, et al. The photoperiod, circadian regulation and chronodisruption: the requisite interplay between the suprachiasmatic nuclei and the pineal and gut melatonin. J Physiol Pharmacol 2011;62(3):269-274

14 Erren TC, Falaturi P, Morfeld P, Knauth P, Reiter RJ, Piekarski C. Shift work and cancer: the evidence and the challenge. Dtsch Arztebl Int 2010;107(38):657-662

15 Joshi A, Mehta CS, Dave AR, Shukla VD. Clinical effect of Nirgundi Patra pinda sweda and Ashwagandhadi Guggulu Yoga in the management of Sandhigata Vata (osteoarthritis). Ayu 2011;32(2):207-212

16 Rajani A, Vyas MK, Vyas HA. Comparative study of Upavasa and Upavasa with Pachana in the management of Agnisada. Ayu 2010;31(3):351-354

17 Turget M, Kumar R. The Pineal Gland and Melatonin: Recent Advances in Development, Imaging, Disease, and Treatment. Illustrated ed. Endocrinology Research and Clinical Developments. New York, NY: Nova Science Publishers; 2012 